\title{
The Effects of Administration of Mangosteen Pericap's Ethanolic Extract and Xanthone on Angiogenesis of Gastric Ulcer Healing in Wistar Rats Observed Through the Increase in the level of NO and VEGF and CD-31 Expressions
}

\author{
Ika Kustiyah Oktaviyanti” ${ }^{1 *}$, Djanggan Sargowo², Aris Widodo ${ }^{3}$, Karyono Mintarum $^{4}$
}

\begin{abstract}
1Doctoral Program Student at Medical Science, Graduate School of Medicine, University of Brawijaya, JI. Veteran, Malang, Indonesia ${ }^{2}$ Cardiology Department at Saiful Anwar General Hospital, Faculty of Medicine, University of Brawijaya, Jl. Veteran, Malang, Indonesia ${ }^{3}$ Pharmacology Department, Faculty of Medicine, University of Brawijaya, Jl. Veteran, Malang, Indonesia ${ }^{4}$ Pathology Departement, Faculty of Medicine, University of Brawijaya, Jl. Veteran, Malang, Indonesia *Correspondence: ikaoktaviyanti@ymail.co,
\end{abstract}

\section{Abstract}

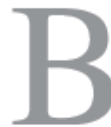

ACKGROUND: NSAIDs can cause gastric ulcer or may delay the healing of it. Upon exposure to indomethacin, gastric ulcer can occur due to oxidants. Mangosteen rind contains xanthone, which is a natural antioxidant. Administration of this antioxidant may increase angiogenesis that can accelerate healing of gastric ulcer.

METHODS: This study used an experimental method with randomized post test control only design using Wistar rats. The rats were put on fasting for 24 hours, then a single dose of $30 \mathrm{mg} / \mathrm{kg}$ body weight (BW) Indomethacine was given. The rats were divided into control group and treatment group. The treatment group was further divided into two subgroups: one group was given a daily $200 \mathrm{mg} / \mathrm{kg}$ BW mangosteen pericap extract, and the other group was given $35 \mathrm{mg} / \mathrm{kg}$ BW Xanthone. Both the control group and treatment group were decapitated on the 3rd day, 6th day, and 12th day, respectively. After decapitation, the stomach ofeach rat was taken and divided into two portions, one portion was used for NO examination by ELISA, and the other portion for hispathological examination and imunohystochemical analysis for assessing CD 31 and VEGF expressions.
RESULTS: Administration of mangoosteen pericap and xanthone could accelerate healing of gastric ulcers as compared with the control, as shown by the decrease in the severity level of the ulcers. Mangoosteen pericap and xanthone could also increase NO, VEGF expression, and CD-31 as compared with the control, especially on the 3rd day of treatment. Explanation of this finding might be that the antioxidants contained in the mangoosteen pericap or in xanthone could bind with radical superoxide and accelerate release of free NO. The increase of NO caused increase of VEGF and CD-31 that could accelerate angiogenesis, which eventually could accelerate healing of the gastric ulcers.

CONCLUSIONS: The effect of mangosteen pericap's extract and xanthone can improve healing of gastric ulcers by increasing nitric oxide and also can increase angiogenesis as shown by the increase of VEGF and CD31 expressions.

KEYWORDS: Mangosteen, Healing of Gastric Ulcer, Angiogenesis

Indones Biomed J 2011; 3 (3): 191-199 


\section{Introduction}

However, the long use of NSAIDs can develop gastric ulcers and may delay gastric ulcer healing (1). NSAIDs may delay healing of gastric ulcers possibly by inhibiting angiogenesis, which is one of the causes for the delay of healing (2). NSAIDs inhibit angiogenesis through direct effects on endothelial cells (3).

Inhibition of angiogenesis may prolong the healing time of gastric ulcers. It was reported that administration of alendronate and indomethacine might decrease the expression of both VEGF and bFGF proteins on the ulcer mucosa resulting in decreased angiogenesis process on the ulcer base, and consequently prolong the healing time of ulcers in rats induced by acetic acid (4).

Angiogenesis signaling until the occurrence of angiogenesis involves complex pathways including the formation of a growth factor (VEGF), binding of VEGFR on the plasma membrane which then activates intracellular signaling pathways of MEK, thus activating ERK to form additional endothelial cells (5). There are some factors that are connected with the increase of VEGF, one of which is NO production. Chin and colleagues showed that NO donor increased stability of mRNA VEGF. The increase of VEGF synthesis by cancer cells from NO was also proven by Ambs and colleagues (16).

Water and ethanol $(50 \%)$ in mangosteen pericap extracts were shown to have high antioxidant activity. A study by Fan \& Su in 1997 reported that alpha-and gamma-mangosteen demonstrated antioxidant activity (6). The study by Chin et al. revealed the hydroxyl radical scavenging activity of some xanthones isolated from mangosteen powder (7). Regarding peroxynitrite as the reaction product of superoxide radical with nitric oxide, Jung et al. (6) have shown that 13 xanthones have peroxynitrite scavenging capabilities as a reaction product of superoxide radical with nitric oxide.

The purpose of this study was to assess the effect of mangosteen pericap extract and xanthone in improving healing of gastric ulcers by increasing nitric oxide and increasing expression of VEGF and CD-31.

\section{Methods}

\section{STUDY DESIGN}

This study used experimental design with randomized control test post only, using Wistar rats.

\section{STUDY SUBJECTS}

Subjects were male Wistar rats of Sprague Dawley strain obtained from Gadjah Mada University Yogyakarta, aged 12 weeks, weighing $150-180 \mathrm{~g}$, in healthy condition.

\section{STUDY MATERIALS}

\section{Material for ulcer induction}

Tablets of indomethacin $30 \mathrm{mg} / \mathrm{kg}$ BW were crushed with water plus $\mathrm{NaOH}$. The use of $\mathrm{NaOH}$ was to make the tablets in pieces in order to go down easily. It is administered orally using a feeding tube into the rats' stomachs, administered as a single dose.

\section{Mangosteen pericap extract material}

Material of mangosteen pericap that was suitable for consumption was derived from South Kalimantan. The mangosteen pericap was separated from its flesh material and impurities were purged completely; the extraction method was done according to Harbone (7).

\section{Xanthone material}

Xanthone was in the form of Xanthone $25 \mathrm{~g}$ of nacalai tesque with Z0E3701 batch number and 36516-92 code.

\section{Materials to make paraffin blocks of the gastric tissues}

The materials required included buffered formalin, alcohol 80\%, 90\%, absolute alcohol, xylene, paraffin, tape blocks, glass objects, micro pipettes and pipette, ethylene, and glass decks. 


\section{STUDY PROCEDURES}

Rats aged 12 weeks (150-180 g) were fed with normal diet and allowed to drink ad libitum. The rats were kept at room temperature of $25 \pm 2^{\circ} \mathrm{C}, 65-70 \%$ humidity, in day and night cycle $(12 \mathrm{~h} / 12 \mathrm{~h})$. Ulcers in the rats' stomachs were induced by putting them in fasting for 24 hours and by giving them a dose of $30 \mathrm{mg} / \mathrm{kg} \mathrm{BW}$ of indomethacin using a gastric probe. The extract-treated pericap group was administered with a single dose of $200 \mathrm{mg} / \mathrm{kg}$ per day for 7 days. The xanthone group was administered with a single dose of $35 \mathrm{mg} / \mathrm{kg}$ BW per day for 7 days. The first doses of mangosteen pericap extract and xanthone were administered 4 hours after the administration of indomethacin.

The rats were divided into 3 major groups, namely the groups of healing on day 3 , healing on day 6 , and healing on day 12, respectively. Each of these major groups was divided into 3 subgroups: control healing group, the mangosteen pericap extract-treated healing, and the xanthone healing.

\section{METHOD OF NO DETERMINATION}

In this study, gastric tissue was divided into 2 parts, one part was crushed for checking of NO level by ELISA method, and the other part was for checking by hispathological examination and imunohystochemical analysis. NO level was assessed by spectrophotometry with a frequency of $540 \mathrm{~nm}$.

\section{METHOD OF MICROSCOPIC EXAMINATION}

Gastric tissues were fixed in buffered formalin solution for histopathological preparations stained with routine HE. The slides were examined under a microscope with a magnification of 40,100 and 400xs, respectively. They were observed in 10 fields, then averaged.

Assessment of the severities of the gastric histopathology:

- Severity level 0: there were no surface cell degeneration, necrosis or hyperemia or gland degeneration; nor mild inflammatory cell infiltration (less than 20 cells/field of view).
- Severity level 1: there were no surface cell degeneration, necrosis, or gland degeneration; mild hyperemia, mild inflammatory cell infiltration (less than 20 cells/field of view) to moderate (20-50 inflammatory cells/field of view).

- Severity level 2: there was mild degeneration of the surface cells; no necrosis, mild to moderate hemorrhage, no gland degeneration, moderate inflammatory cell infiltration (20-50 inflammatory cells/field of view) to severe inflammation (more than 50 inflammatory cells/field of view).

- Severity level 3: there were moderate to severe surface cell degeneration, necrosis, moderate to severe hyperemia, gland degeneration, and severe inflammatory cell infiltration (more than 50 inflammatory cells/field of view).

\section{METHOD OF VEGF AND CD-31 EXAMINATIONS}

VEGF and CD-31 were examined by imunohispathochemical method. The scoring for VEGF expression are below :

0: negative: if the vascular endothelial cells did not express brown color in their cell cytoplasm.

1: slightly positive, when the vascular endothelial cells expressed a slight brown color in the cytoplasm

2: moderately positive, if the vascular endothelial cells expressed a brown color on some cell cytoplasm.

3: strongly positive, if the vascular endothelial cells expressed a dark brown color on some endothelial cell cytoplasm.

For assessing CD-31 expression, observation was made on 10 fields of view, after which the number of cells per field of view was averaged. All data obtained were averaged and compared between rind extract-treated group, xanthone group and the control group in every group. 


\section{Results}

\section{MICROSCOPIC OBSERVATION}

There were significant differences in healing on the $3^{\text {rd }}$ day (sig $<\alpha 0.010<0.05), 6^{\text {th }}$ day (sig $<\alpha 0.003<0.05$ ), and on the $12^{\text {th }}$ day ( $\operatorname{sig}<\alpha 0.002<0.05$ ), with the highest ulcer severity level is for ulcer, and the lowest was seen in mangoosteen pericap extract.

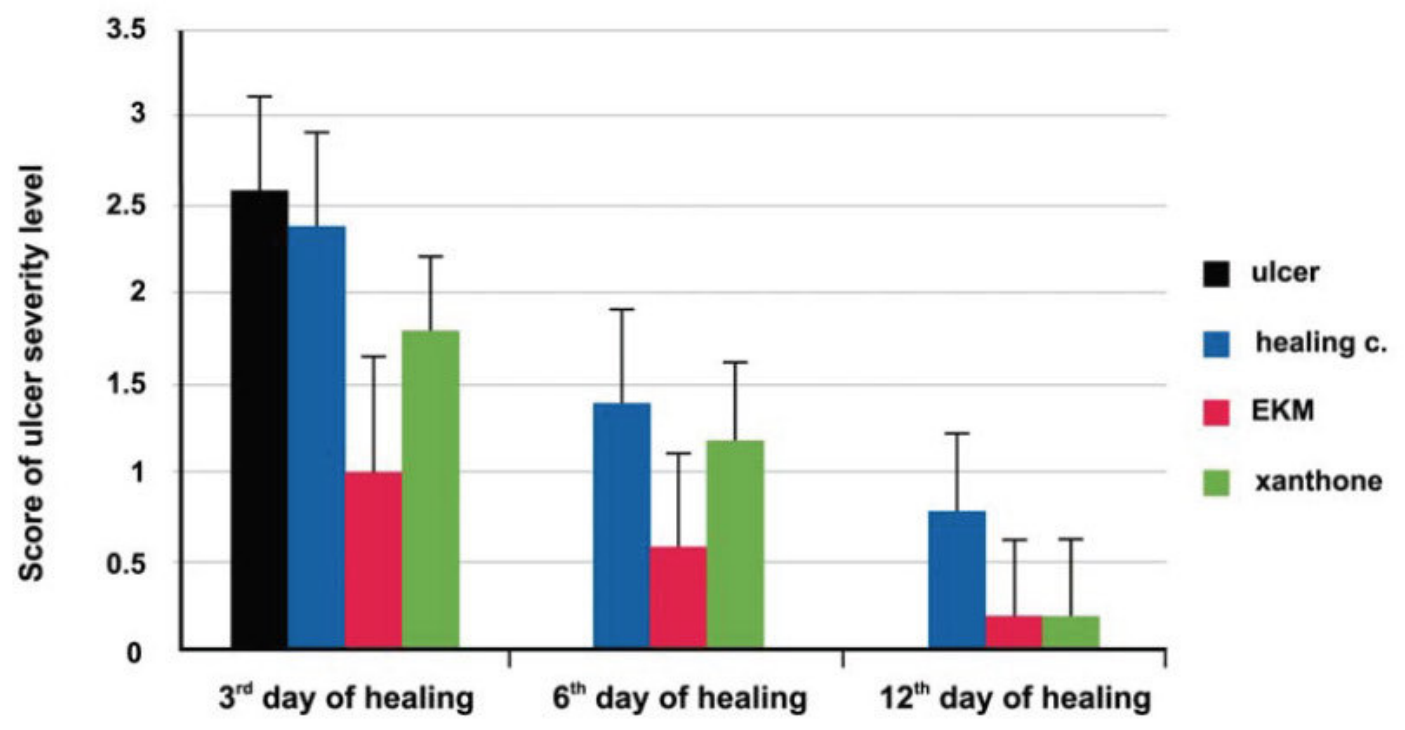

Figure 1. Microscopic observation score in healing gastric ulcer.

Designation of inflammation cells and degeneration of epithelial surface and necrosis seemed to decrease day by day and with the allocation of mangosteen pericap and xanthone, they became reduced as compared with the control.

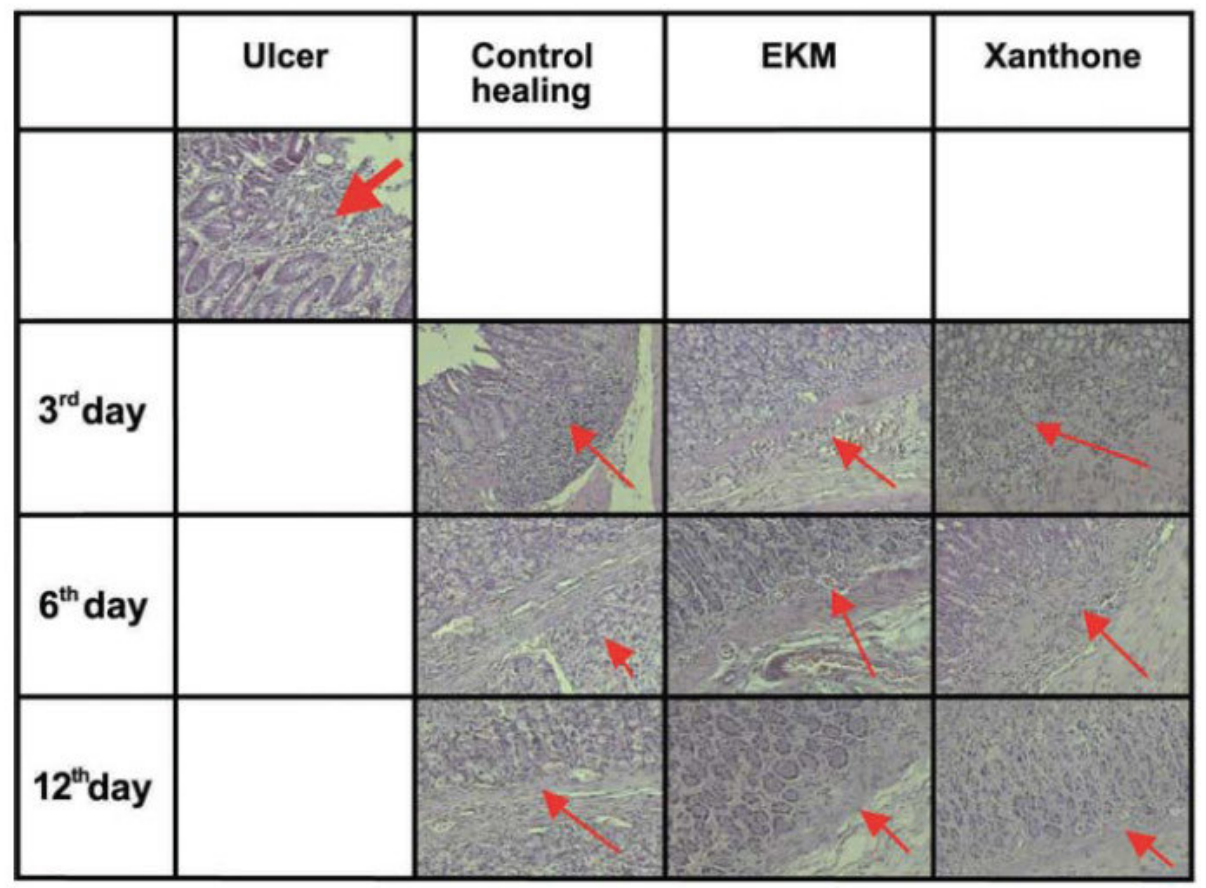

Figure 2. The effects of mangosteen pericap extract and Xanthone on ulcers' healing microscopically. 


\section{NO LEVEL}

There was increase of NO level with significant differences on the $3^{\text {rd }}$ day $(\operatorname{sig}<\alpha 0.001<0.05)$ and on the $6^{\text {th }}$ day $(\mathrm{sig}<$ $\alpha 0.057<0.05$ ), whereas allocation of mangosteen pericap showed the highest NO level. On the other hand, there was no significant difference seen on the $12^{\text {th }}$ day (sig $>\alpha$ $0.0101>0.05)$.

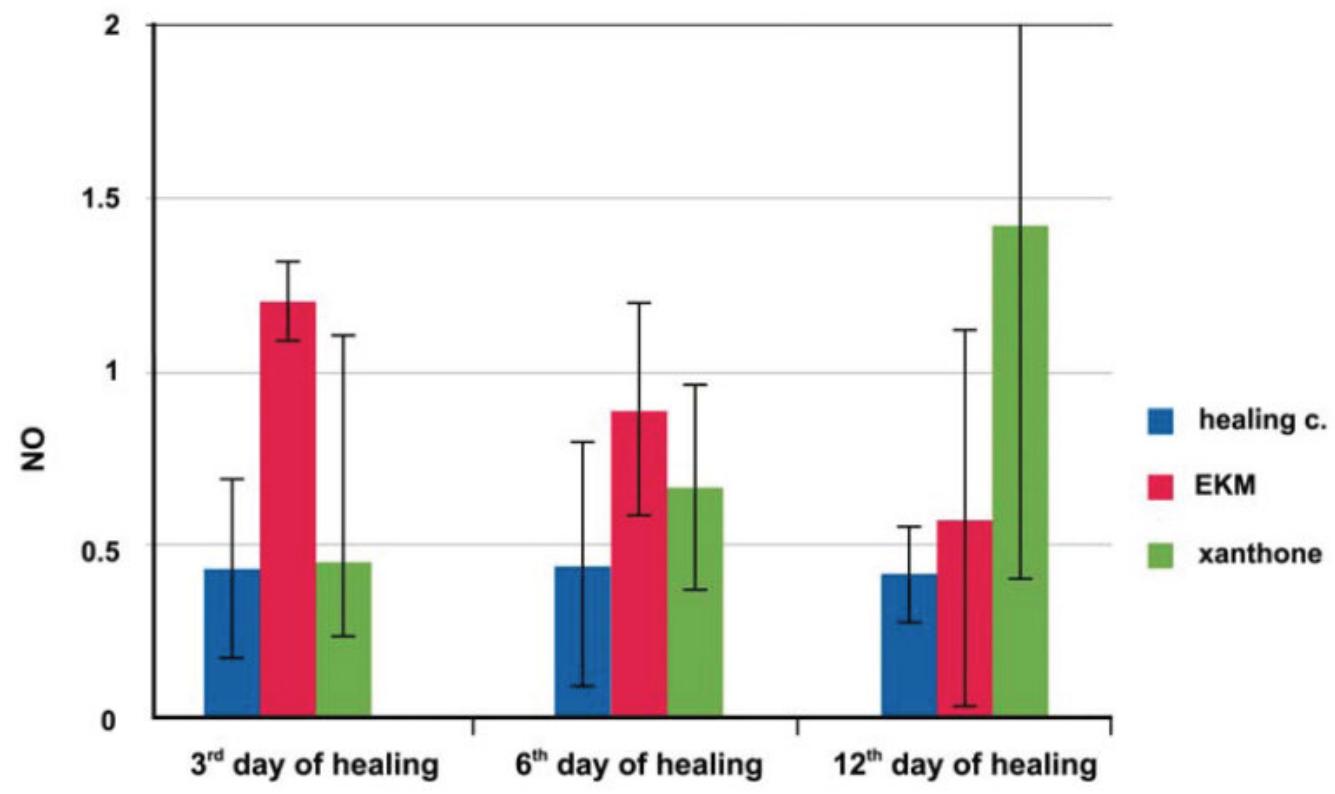

Figure 3. NO level on healing day 3, 6 and 12.

\section{VEGF EXPRESSION}

The microscopic slides were stained for imuno- histochemical analysis for VEGF expression, the results of which are shown in Figure 4a and 4b.

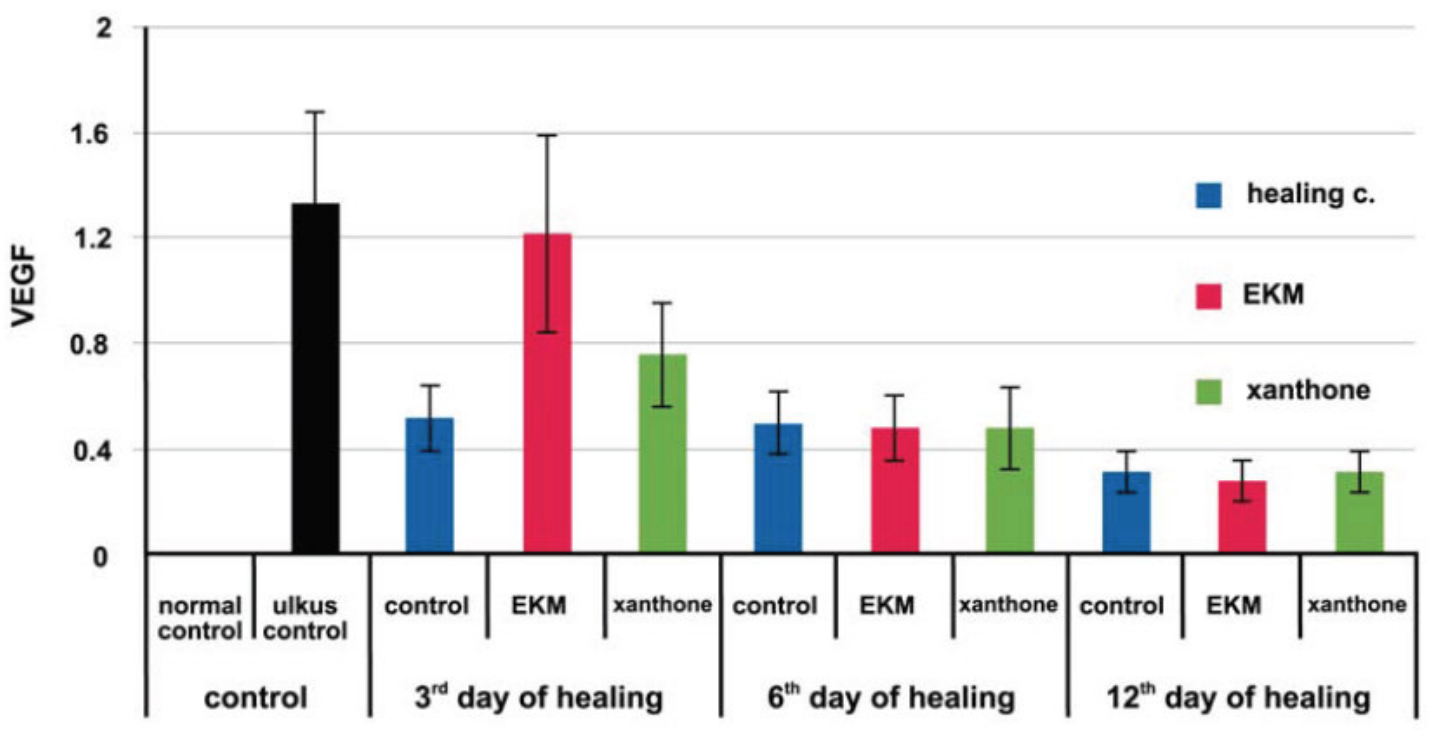

Figure 4a. VEGF expression 
There was an increase of VEGF on the $3^{\text {rd }}$ day by the allocation of mangosteen pericap with a significant difference (sig $<\alpha 0.005<0.05$ ), and on the $6^{\text {th }}$ day and the $12^{\text {th }}$ day, no significant differences were found.

The strongest VEGF expression was seen when it was allocated with mangosteen pericap on the $3^{\text {rd }}$ day on the ulcers. Moreover, medium VEGF expression was noted when it was allocated with xanthone on the $3^{\text {rd }}$ and 6th days, with mangosteen pericap on the 6th day, and control on the $3^{\text {rd }}$ and $6^{\text {th }}$ day. The least VEGF expression developed on the $12^{\text {th }}$ day of each of the three groups.

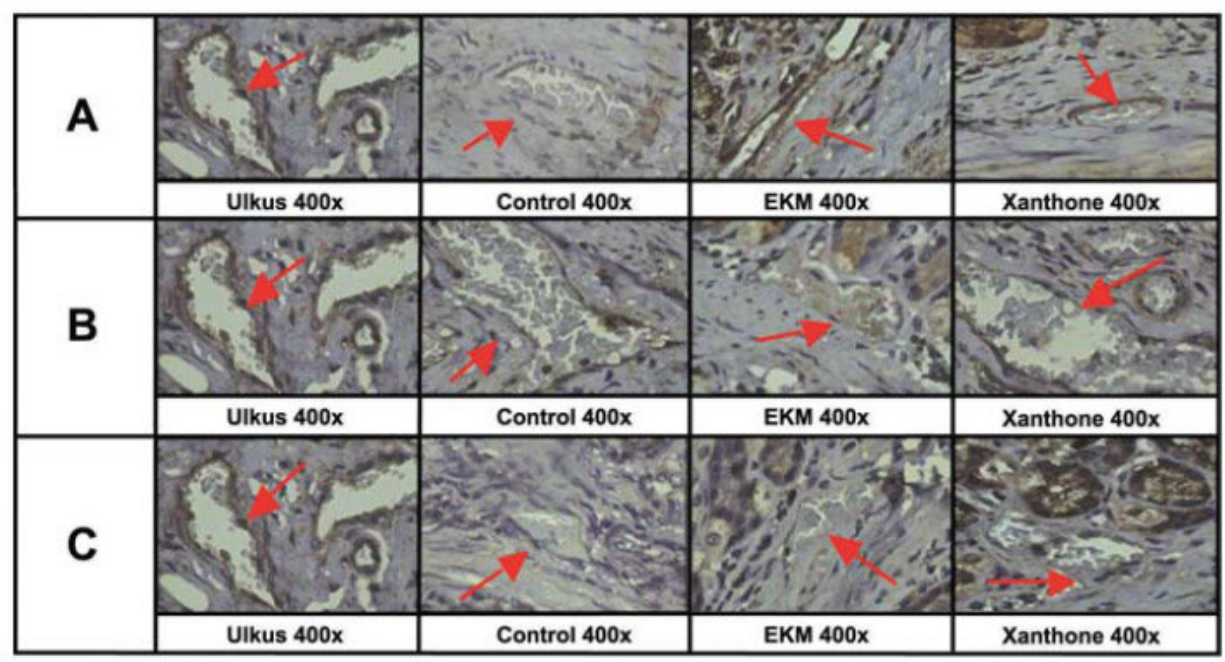

Figure 4b. The effects of mangosteen pericap extract and Xanthone on VEGF expressions on the $3^{\text {rd }}(A), 6^{\text {th }}(B)$, and $12^{\text {th }}(C)$ day of healing.

\section{CD-31 EXPRESSION}

There was increased number of cells that expressed CD-31 in the mangosteen pericap (EKM) group with a significant difference ( $\operatorname{sig}<\alpha 0.000<0.05)$ on the $3^{\text {rd }}$ day. On the $6^{\text {th }}$ day, increased number of cells that expressed CD-31 was seen in the xanthone group with significant difference $($ sig $<\alpha 0.000<0.05)$. Similarly, on the $12^{\text {th }}$ day with a significant difference $(\mathrm{sig}<\alpha 0.000<0.05$ ), whereas the EKM group had the greatest average in the number of cells that expressed CD-31 (fig 5).

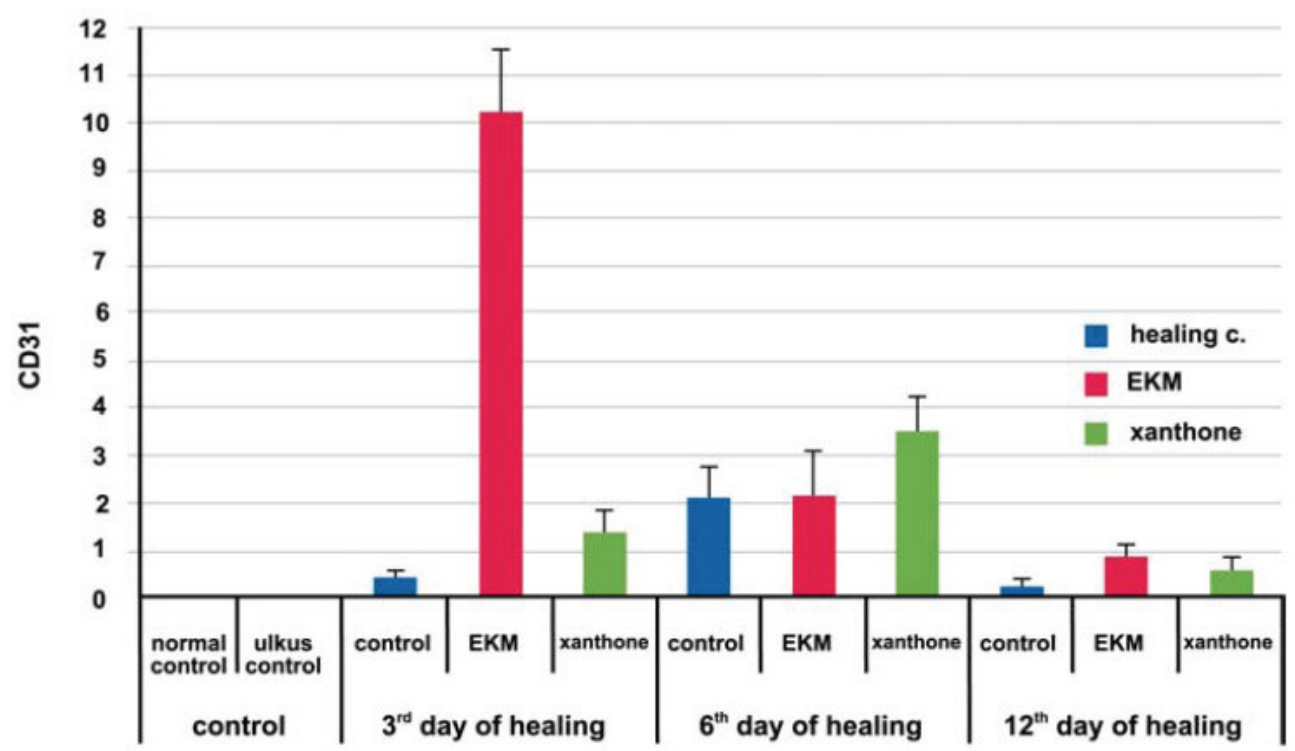

Figure 5a. CD-31 expression. 


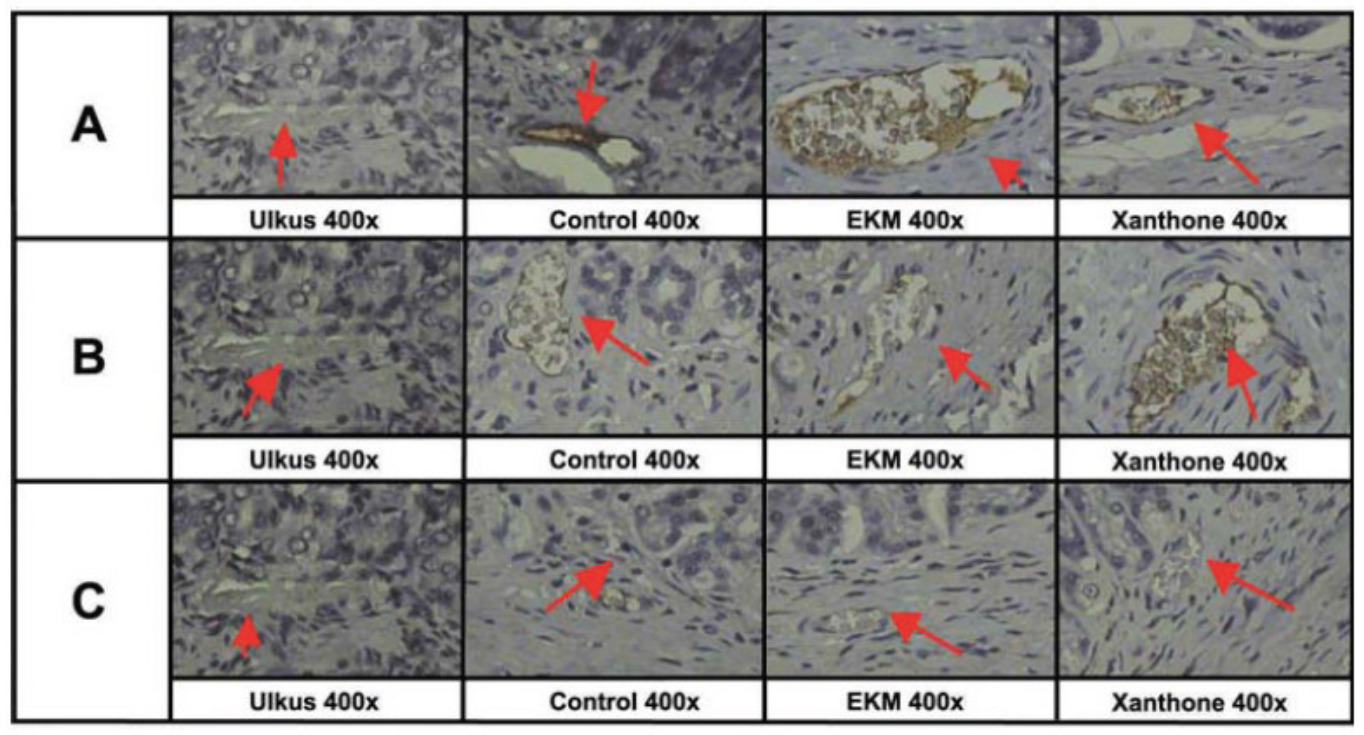

Figure 5b. The effects of mangosteen pericap extract and Xanthone on CD31 expressions on the $3^{\text {rd }}(A), 6^{\text {th }}(B)$, and $12^{\text {th }}(C)$ day of healing.

\section{Discussion}

This study found significant reduction in the severity of ulcers in the mangosteen pericap extract-treated group and xanthone group compared with the control in all phases of healing, as shown in Figure 1. This may be due to the effect of antioxidants contained in the mangosteen pericap extract and xanthone. Mangosteen pericap extract used here contained flavonoids, alkaloids, saponin, and tannins which are natural antioxidants. It can be concluded that the effect of administration of mangosteen pericap extract was better than that of xanthone, in regard with increasing healing of gastric ulcers.

\section{Nitric oxide (NO)}

In this study, the levels of NO in the pericap extracttreated group were higher than those in the control group. This might be due to the fact that pericap extract had the features as an antioxidant that can capture the oxidants generated in the ulcers, especially in the inflammatory phase. Since reactive oxygen is bound to antioxidants from the mangosteen pericap extracts, the unbound NO will become more abundant. At this study, NO level that was allocated with EKM increased as compared with the control. This finding might be due to the flavonoid in EKM, which is also an antioxidant which can take oxidant radical superoxyde in the ulcer. It makes the radical superoxyde set free from NO, so to develop peroxynitrite. The free $\mathrm{NO}$ increased at the allocation of EKM as compared with the control.
Neungton et al. have found that mangosteen pericap extract can protect SK-N-SH cells against the betaamyloid that induces the formation of reactive oxygen compounds (ROS) (8). Furthermore, Moongkarndi et al. have demonstrated the potential of mangosteen extracts to reduce production of intracellular reactive oxygen compounds with 2.7-dichlorofluorescein diacetate (DCFH -DA) parameter on SKBR3 cell line. (9)

Furthermore, in the xanthone group, NO level on day 3 was not different from that in the control, probably due to the fact that antioxidant effect of xanthone was less strong than the effect of the pericap extract. Chin et al. (5) revealed that oxidant scavenging activities of some xanthones isolated from the mangosteen powder were different. Only alpha-mangosteen from 16 xanthones tested showed scavenging activity against hydroxyl radical $\left(\mathrm{IC}_{50}=0.2 \mu \mathrm{g} / \mathrm{mL}\right)$.

However, after 6 days of usage, NO level was higher compared with normal control, and increased higher after the $12^{\text {th }}$ day, although the xanthone administration was stopped after the $7^{\text {th }}$ day. This might be due to the fact that xanthone has an effect after its administration for a longer time and that it might contain elements that can stimulate cells to produce NO.

NO level in the pericap extract-treated group observed on days 6 and 12 showed a strong tendency to decline. This might be related to the phase of healing where oxidants would be generated in larger quantities when the ulcers had occurred as well as at the inflammatory phase, so the increase in NO due to the addition of antioxidants gave stronger impacts on the inflammatory phase, as shown on day 3 . 


\section{VEGF}

Vascular endothelial growth factor (VEGF) is a $34-42 \mathrm{kDa}$ homodimeric protein as a potent and fundamental regulator of normal and abnormal angiogenesis (10). VEGF is also known as vascular permeability factor (11).

In this study, VEGF expression appeared to increase in the ulcers. This might be due to hypoxia that developed in the presence of ulcers. Hypoxia is the main controller of angiogenesis through the induction of hypoxia inducible factor (HIF). Hypoxic condition induces increased expression of HIF-1 $\alpha$ (a subunit of HIF-1), which regulates VEGF at the transcriptional period and post transcriptional time (11).

On day 3, the expression of VEGF increased significantly in the group administered with mangosteen pericap extracts as compared with the control. Similarly, in the group administered with xanthone, there was increased expression of VEGF as compared with the control. However, VEGF expression in the xanthone group was lower than that in the pericap extract-treated group.

On day 6, the expression of VEGF in the pericap extract-treated group decreased, and reduced further on day 12 , but it was still greater as compared wuth the control group. This suggests that the effect of the mangosteen pericap extract, which enhanced the expression of VEGF, could be apparently observed on day 3 . The angiogenic process itself actually began at the proliferative phase with increased VEGF expression on days 4 to 7 (12). But in this study, VEGF expression increased on day 3 in the pericap extract-treated group and in the xanthone group. It can be concluded that EKM and xanthone can accelerate angiogenesis.

\section{CD-31}

CD-31 is adhesion molecule of endothelial cells, which plays a role in adhesion among endothelial cells in forming the tubular blood vessels resulting in angiogenesis (13). Angiogenesis itself at the healing stage occurs in the proliferative phase, which is on day 4 to 7 (12). In this study, the expression of CD-31 in the control group was found to increase in the healing process on day 6 as compared with day 3 .

In this study, CD 31 appeared to increase on day $3 \mathrm{inl}$ the pericap extract-treated group, suggesting that administration of mangosteen pericap extract could accelerate the timing of angiogenesis as evidenced with CD 31. Administration of $x$ anthone showed an extended expression of CD 31 on day 6 , in contrast to mangosteen pericap extract. However, the expression of CD 31 in the xanthone group was greater than that in the control. This suggests that xanthone can enhance expression of CD 31 , but does not accelerate the timing of angiogenesis as seen through CD 31. The expression of CD 31 in the pericap extract-treated group was greater than that in the xanthone group.

\section{Angiogenesis}

Angiogenesis is the process by which new blood vessels arise from the existing vessels, playing an essential role in embryonic development and later in adult life as a physiological process (e.g., corpus luteum formation) and in pathological conditions such as tumor and chronic inflammatory process that leads to disease progression (14).

In this study there was a direct correlation found between the level of NO and VEGF expression ion the $3^{\text {rd }}$ day $(\mathrm{p}=0.004)$, by 0.568 regression coefficient, 0.609 path coefficient, and $\mathrm{R}^{2}=0.371$. It means that the increase of NO affects the increase of VEGF by $37,1 \%$. This is consistent with the result of a study that reported the expression of ecNOS (endothelial constitutive NOS) gene and its production of NO induced VEGF expression in vascular smooth muscle cells of rats. When the formation of NO by NOS is inhibited by L-NAME or DAHP, VEGF synthesis will decrease. And when the formation of NO is enhanced with the addition of L-arginine and $\mathrm{BH} 4$, synthesis of VEGF will return to normal. Synthesis of NO can increase the expression of VEGF presumably through the mechanism of $\mathrm{NO}$ altering transcription and stability of mRNA VEGF (15).

Another study seemingly supporting this statement has found that there was increased synthesis of VEGF by cancer cells through NO (16), and the study by Ye et al. has reported that nitric oxide could induce VEGF synthesis in vascular smooth muscle cells, tumor cells, and keratinocytes. Nitric oxide not only acts as a downstream mediator of VEGF signaling, but also contributes directly to the upstream mediator and induces VEGF synthesis (11).

However, no correlation was found between $\mathrm{NO}$ and VEGF expression on days $6(\mathrm{p}=0.936)$ and $12(\mathrm{p}=0.678)$. This might be due to the fact NO affects VEGF synthesis only in the early process of angiogenesis occurring at the proliferative phase, where in the administration of xanthone and mangosteen pericap extract, the initial proliferative phase took place on day-3.

Angiogenesis can also be determined using CD-31 that is an adhesion molecule of endothelial cells, which plays a role in adhesion between endothelial cells in forming the tubular blood vessels (13).

In this study, no corelation was found between VEGF and CD 31 at the $3^{\text {rd }}$ day $(\mathrm{p}=0.118)$, the $6^{\text {th }}$ day 
$(\mathrm{p}=0.766)$, and the $12^{\text {th }}$ day $(\mathrm{p}=0.948)$. This might be due to the fact there is a factor influencing the process of angiogenesis since VEGF expression until the occurrence of angiogenesis.

Several studies have shown that NO can affect the ERK1/2 pathways in generating cell proliferation, although this is still debatable. NO seems to influence Ras and both its stimulatory and inhibitory effects, which may occur through S-nitrolization (17). Pilz stated that the response to NO could affect the activation of cGMP in activating MAPK through which ERK gene is expressed, but it is also dependent on the cell type and growth condition (18).

Some researchers say that the action of ERK is triggered by VEGF stimulation under influence of the presence of NO. NO activates ERK by stabilizing the mRNA in the MAPK (19). Activation of kinase-derived receptor (KDR) stimulates NO synthesis/guanylate cyclase pathways to activate the MAPK cascade which then activates ERK1/2, which is the essence of endothelial cell proliferation induced by VEGF.

In this study, there was a correlation between $\mathrm{NO}$ and CD 31 on the $3^{\text {rd }}$ day $(p<0.001)$ with 7,698 regression coefficient and 0.699 path coefficient. It means that the increase of $\mathrm{NO}$ gives effect to the increase of CD-31. The contribution of NO and VEGF to CD-31 is 76,8\% $\left(\mathrm{R}^{2}=0.768\right)$. Thus, it can be concluded that $\mathrm{NO}$ has an important role in angiogenesis process until CD31 is expressed. There is a possibility of NO is needed for ERK activation until proliferation endothelial cells and expressed CD 31 for building up the tubular blood vessels resulting in angiogenesis. From those references it was clear that NO affects VEGF process and induces development of angiogenesis until CD-31 is expressed to make up new blood vessels, which is also affected by the availability of NO.

\section{Conclusion}

From this study, it can be concluded that allocation of EKM and xanthone can increase gastric ulcers' healing by increasing angiogenesis as evidenced by the increase of VEGF and CD-31 expressions.

\section{Acknowledgements:}

We thank Harijadi, dr. SpPA for immunohistological consultation.

\section{References:}

1. Perini R, Ma Li, Wallace JL. Roles of platelets and proteinaseactivated receptors in gastric ulcer healing. Dig Dis Sci. 2005; 50 Suppl 1: S12-5.

2. Tarnawski AS. Cellular and Molecular Mechanisms of Gastrointestinal Ulcer Healing. Dig Dis Sci. $2000 ; 50$ Suppl 1: S24-33

3. Jones MK, Wang H, Peskar BM, Levin E, Itani RM, Sarfeh IJ, et al. Inhibition of Angiogenesis by Nonsteroidal Anti-inflamatory Drugs : insight into Mechanisms and Implications for Cancer Growth and Ulcer Healing. Nat Med. 1999. ;5: 1418-23.

4. Amagase K, Hayashi S, Nishikawa K, Aihara E, Takeuchi K. Impairment of Gastric Ulcer Healing by Alendronate, a Nitrogen-Containing Bishposphonate in Rats. Dig Dis Sci. 2007; 52: 1879-89.

5. Ferrara N.. Role of vascular endothelial growth factor in regulation on physiological angiogenesis. Am J Physiol Cell Physiol. 2001; 280: C1358-6.

6. Fan C, Su J. Antioxidative mechanism of isolated components from methanol extract of fruit hulls of G. Mangostana L.. Journal Chinese Agricultural Chemistry Society. 1997; 35: 540-51.

7. Chen F, Castranova V, Shi X, Demers LM. New insight into the role of nuclear factor-kB, a ubiquitous transcription factor in the initiation of disease. Clin Chem. 1999; 45: 7-17.

8. Neungton N, Moongkardi P, Srisawat C, Jantaravinid J, Peerapitayamonkol C, Soi-ampornkul $\mathrm{R}$, et al. Protective effect of mangosteen extract against amyloid induced apoptosis in SK-N-SH-cells. J Proteome Res. 2010; 9: 2076-86.

9. Moongkarndi P, Kosem N, Kaslunga S, Luanratana O, Pongpan $\mathrm{N}$, Neungton N. Antiproliferation, antioxidation and induction of apoptosis by Garcinia mangostana (mangosteen) on SKBR3 human breast cancer cell line. J Ethnopharmacol. 2004; 90: 161-6.

10. Dai J, Rabie ABM. VEGF: an essential mediator of both angiogenesis and endochondral ossification. J Dent Res. 2007 ;86: 937-50.

11. Ye L, Haider HK, Jlang S, Sim EKW. Therapeutic angiogenesis using vascular endothelial growth factor. Asian Cardiovasc Thorac Ann. 2004; 12: 173-81.

12. Braiman-Wiksman L, Solomonik I, Spira R, Tennenbaum T. Novel insights into wound healing sequence of events. Toxicol Pathol. 2007; 35: 767-79.

13. Delisser HM, Solomidon MC, Strieter RM, Burdick MD, Robinson CS, Wexler RS, et al. Involvement of endothelial PECAM-1/ CD31 in angiogenesis. Am J Pathol. 1997. ;151: 671-7

14. Ribatti D, Conconi MT, Nussdorfer GG. Nonclassic endogenous novel regulators of angiogenesis. Pharmacol Rev. 2007; 59: $185-205$.

15. Dulak J, Józkowicz A, Kiec AD, Guevara I, Zdzienicka A, Grochot DZ et al. Nitric Oxide Induces the Synthesis of Vascular Endothelial Growth Factor by Rat Vascular Smooth Muscle Cells. Arterioscler Thromb Vasc Biol. 2000; 20: 659-66.

16. Ambs S, Merriam WG, Bennet WP, Felley-Bosco E, Ogunfusika $\mathrm{MO}$, Oser SM, et al. Frequent nitric oxide synthase-2 expression in human colon adenomas: implication for tumor angiogenesis and colon cancer progression. Cancer Res. 1998; 58: 334-41.

17. Tziomalos K, Hare JM. Role of xanthine oxidoreductase in cardiac nitroso-redox imbalance. Front Biosci. 2009; 14: 237-62.

18. Pilz RB, Broderick KE. Role of Cyclic GMP in gene Regulation. Front Biosci 2005; 10: 1239-68.

19. Wang S, Zhang J, Theel S, Barb JJ, MUNson PJ, Danner RL. Nitric oxide activation of Erk1/2 regulates the stability and translation of mRNA transcripts containing CU-rich elements. Nucleic Acids Res. 2006; 34: 3044-56. 